\title{
ESTUDIO LITERARIO DE LOS LIBROS DE VIAJES MEDIEVALES
}

Miguel angel Pérez Priego

U.N.E.D.

El relato de viajes tuvo en la Europa medieval un intenso cultivo literario. Peregrinos, mercaderes, embajadores, caballeros y gentes muy diversas recorrieron una y otra vez las partidas del mundo $y$ en ocasiones dejaron testimonio escrito de sus experiencias, $y$ también a veces de sus sueños y fantasías. Se creó así una copiosa literatura que abarca gran variedad de formas y modalidades: guías y relatos de peregrinación (los primitivos itineraria y descripciones de Tierra Santa, o los más modernos y personales libros de peregrinación de Ricoldo de Montecroce o Burchard de Monte Sión, de comienzos del siglo XIII), relaciones de misioneros y embajadores (las embajadas a Mongolia de los franciscanos Giovanni da Pian del Carpine y Guillermo de Rubruk en 1245 y 1253, respectivamente, o las más fantásticas descripciones de Oriente de Odoric de Pordenone y el monje Jordanus), relatos de exploradores y aventureros (cuyo modelo clásico es el libro de Marco Polo, de fines del siglo xiII en su primera redacción), e incluso viajes imaginarios y fingidos (como los famosos Viajes o Libro de las maravillas del mundo, de John Mandeville, ca. 1350) '.

1 Para estas modalidades y tipología del libro de viajes, vid. la excelente síntesis de Jean Richard, Les récits de voyages et de pèlerinages, Turnhout, 1981, especialmente págs. 15-36. Sobre los viajeros europeos de la Edad Media, sus testimonios y descubrimientos, pueden verse, entre otros estudios fundamentales: YULE, Henry: Cathay and the way thither, being a collection of medieval notices of China, London, 1866, 2 vols.; Travel and Travellers of the Middle Ages, ed. by Arthur Percival Newton, London, 1926; LecLerco, H.: «Itinéraires* y «Pèlerinages 
En la literatura española, sobre todo desde la segunda mitad del siglo xIV y a lo largo de todo el siglo $\mathrm{XV}^{2}$, cobraron también notable desarrollo este tipo de escritos, y se documenta una apreciable serie de obras que se adscriben a los distintos géneros europeos y hasta pueden competir con sus mejores modelos. En efecto, como muestra de relato de viajes fingido contamos con el Libro del conosçimiento de todos los reinos e tierras e señorios que son por el mundo, escrito hacia 1350 por un anónimo franciscano, probablemente de Sevilla ${ }^{3}$. Al género de las relaciones de embajadores pertenece la célebre Embajada a Tamorlán, en la que se narra la misión diplomática que en 1403 envió Enrique III a Tamorlán, rey de Persia, y que protagonizaron Fray Alonso Páez de Santamaría, Gómez de Salazar y Ruy González de Clavijo, quien seguramente redactó el libro 4 . Un típico relato viajero de aventuras son las Andanças e viajes por diversas partes del mundo avidos, de Pero Tafur, escrito hacia 1454,

aux Lieux Saints», en Dictionnaire d'Archéologie chrétienne et de Liturgie, Paris, 1939, VII, 2, cols. 1841-1922, y XIV, 1, cols. 65-176.

2 No hacemos cuenta aquí de obras como la latina Peregrinatio, de la monja Egeria, en el s. IV, ni de la actividad de los viajeros árabes y hebreos hispanos, entre los que alcanzó particular notoriedad el rabino Benjamín de Tudela, quien en 1160 emprendió viaje a Oriente y a su regreso redactó en hebreo un difundidísimo itinerario (vid. Viajes de Benjamin de Tudela (1160-1173), trad. e intr. de I, González Llubera, Madrid, 1918). Tampoco entramos a considerar escritos en romance de fecha más temprana como La Fazienda de Ultra Mar, singular relación con marco epistolar en la que se describen diversos lugares de Tierra Santa por medio de los correspondientes fragmentos y pasajes bíblicos traducidos del hebreo al romance (vid. Almerich, Arcidiano de Antiochía, La Fazienda de Ultra Mar. Biblia Romanceada et Itinéraire Biblique en prose castillane du XII' siecle, ed. de Moshé Lazar, Universidad de Salamanca, 1965); ni otros más tardíos como la Tribagia o vía sacra de Hierusalem (Roma, 1521), relación en verso de Juan del Encina sobre su viaje a Tierra Santa en 1519 y en el que acompañó al marqués de Tarifa, quien también escribió sus memorias del viaje (ambas obras se publicarian juntas en Lisboa, 1580).

3 Libro del conosçimiento de todos los reynos e tierras e señorios que son por el mundo $e$ de las señales $e$ armas que han cada tierra e señorio por sy $e$ de los reyes $e$ sefiores que los proueen. Escrito por un franciscano español a mediados del siglo xIV y publicado ahora por primera vez con notas de Marcos Jiménez de la Espada, Madrid, 1877. La misma edición, con una presentación de Francisco López Estrada, ha sido reimpresa en Barcelona, Ediciones El Albir, 1980. Una ed. divulgativa sólo del texto apareció en Madrid, A. Pueyo, s. a.

4 Se conservan dos mss. del siglo xv (British Museum, Add. 16613, y B. N. de Madrid, Ms. 9218) y fue editado por G. Argote de Molina en 1582, en Sevilla (esta ed. fue reimpresa, con comentarios de García de Silva, en Madrid, A. de Sancha, 1782; sin las notas de Argote ni los comentarios de Silva, ha sido recientemente publicada en Madrid, Edcs. Miraguano, 1984). En 1943 publico F. López Estrada su estudio y ed. del ms. de la B. N., Madrid, C. S. I. C., 1943. La autoría de Clavijo, ya propugnada por Argote, ha sido defendida con algunas buenas razones por Franco Meregalli, Cronisti e viaggiatori castigliani del Quattrocento, Milán, 1957, págs. 32-83. 
y en el que se cuenta el viaje realizado por este caballero de origen sevillano a diversos lugares de Oriente y Europa entre 1436 y 1439 . Asimismo hay que incluir en la serie, como original muestra de relato novelesco de viajes, el Libro del infante don Pedro de Portugal, obra que por ser sólo conocida en versiones - primero castellanas y más tarde portuguesas- del siglo XVI, y dado el carácter fabuloso de las aventuras que atribuye al infante (muerto en 1449), fue tenida durante mucho tiempo por una invención moderna sobre los legendarios viajes de don Pedro, pero de la que recientemente Harvey $L$. Sharrer ha probado la existencia indudable de una redacción original cuatrocentista que aparece vertida en algunos capítulos del Libro de las bienandanzas e fortunas compilado por Lope García de Salazar entre 1471 y $1476^{6}$. Por último, también conviene integrar en nuestro repertorio las traducciones de algunos muy difundidos libros de viajes europeos, como el de Marco Polo o el de Mandeville, que hubieron de contribuir decisivamente al desarrollo del género en España. En cuanto al primero, conservamos una traducción aragonesa de la versión abreviada del Milione, mandada componer por Juan Fernández de Heredia entre 1377 y 1396, cuando era Gran Maestre de Rodas, aunque la más divulgada fue la traducción de 1503 por Rodrigo Fernández de Santaella, que alcanzó numerosas ediciones a lo largo del siglo xvi ${ }^{7}$. Del libro de Mandeville conocemos también una temprana traducción aragonesa promovida por el rey Juan I a fines del siglo XIV, en tanto que las versiones castellanas sólo se documentan a partir del XVI (siete ediciones de 1515 a 1564) 8 .

5 La obra sólo nos es conocida por una copia manuscrita del siglo xvIII, hoy en la Biblioteca Universitaria de Salamanca, Ms. 1985. La editó por vez primera JIMÉNEZ DE LA ESPADA, M.: Andanças e viajes de Pero Tafur por diversas partes del mundo avidos (1435-1439), Madrid, Col. de Libros Españoles Raros o Curiosos, VIII, 1874. Esta misma ed., más el estudio de J. Vives que citamos en la n. 15, una presentación de F. López Estrada y nuevos índices, ha sido nuevamente publicada en Barcelona, Edics. El Albir, 1982. Hay también una ed. divulgativa de J. M.* Ramos, Madrid, Edit. Hernando, 1934.

6 Sharrer, H. L.: «Evidence of a fifteenth-century Libro del Infante don Pedro de Portugal and its relationship to the Alexander cycles, Journal of Hispanic Philology, I (1977), págs. 85-98. Edición: Gómez de Santisteban, Libro del Infante don Pedro de Portugal, publicado segundo as mais antigas ediçoes por Francis M. Rogers, Lisboa, 1962. Debe verse también RoGERs, F. M.: The Travels of the Infante Dom Pedro de Portugal, Cambridge, Mass., 1961.

7 Juan Fernández de Heredia's Aragonese Version of the aLibro de Marco Polow, ed. John Nitti, Madison, Hispanic Seminary of Medieval Studies, 1980; Libro de las cosas maravillosas de Marco Polo (versión castellana de Rodrigo Fernández de Santaella, Sevilla, 1518 [1503]), ed. Rafael Benítez Claros, Madrid, Sociedad de Bibliófilos Españoles, XX, 1947 (hay reimp., con un pról. de Stéphane Yerasimos, Barcelona-Palma de Mallorca, José J. de Olañeta, 1982).

8 "Libro de las Maravillas del Mundo" de Juan de Mandevilla, estudio y ed. 
Delimitado el corpus de referencia ${ }^{9}$, creemos que puede intentarse ya un estudio literario de estos libros de viajes y un análisis de los rasgos artísticos que los definen y configuran. Si ese análisis resulta válido, podremos contar con algún argumento más para instalarlos definitivamente como categoría genérica y capítulo autónomo en el panorama de nuestra prosa literaria medieval ${ }^{10}$.

\section{El itinerario}

Atendiendo a su orden constructivo, lo primero que puede observarse es que en el libro de viajes la narración se articula básicamente sobre el trazado y recorrido de un itinerario, el cual constituye la urdimbre o armazón del relato, de modo semejante, por ejemplo, a la sucesión de reinados o el sistema de anales en el género cronístico. Todos los libros medievales, desde los antiguos itineraria, a los que dio nombre, hasta las relaciones de embajadas o de aventuras, adoptan, por tanto, la disposición estructural de un itinerario que es seguido desde su comienzo a su final y ocupa toda la extensión de la obra. Únicamente el libro de Marco Polo presenta como singularidad genérica una curiosa alteración del rasgo: allí el itinerario propiamente —el viaje, primero de Nicola y Maffeo Polo,

Pilar Liria Montañés [del ms. aragonés], Zaragoza, 1979; Juan de Mandeville, Libro de las Maravillas del Mundo, ed. facs. [de la de Valencia, 1524], pról. de J. E. Martínez Ferrando, Madrid, Col. Joyas Bibliográficas, 1958-60, 2 vols.

9 A nuestro entender, no deben incluirse en él, frente a lo que algunas veces se ha hecho (así en el estudio de Bárbara W. Fick, El libro de viajes en la España medieval, Santiago de Chile, 1976, sobre el que también debe verse la reseña de F. López Estrada en $R$. F.E., LXI, 1981, págs. 267-270), libros de carácter biográfico y cronístico como El Victorial, de Gutierre Díez de Games, donde el viaje no constituye sino un episodio más de los hechos de armas emprendidos por el protagonista. El que en las crónicas, reales o particulares, así como en los libros de caballerias, aparezca con reiteración el motivo del viaje, no autoriza, sin embargo, a considerarlos inscritos en la misma serie que los relatos viajeros, dado que sus procedimientos constructivos son notoriamente diferentes.

10 En realidad, el interés por los libros de viajes partió de historiadores y geografos del siglo pasado, como Marcos Jiménez de la Espada, que publicó varios de esos textos, o Ángel Lasso de la Vega, autor de un breve pero muy documentado estudio de conjunto (Viajeros españoles de la Edad Media, conferencia de la Sociedad Geográfica de Madrid, 1882). Los historiadores de la literatura han tardado, en cambio, más tiempo en prestarles atención (J. Amador de los Ríos, que aún no tenía noticias del libro de Tafur, sólo dedica algún comentario a la Embajada y a la trad. del libro de Marco Polo, que también transcribe en apéndice), y han sido trabajos como el citado de F. Meregalli o los continuados de F. López Estrada, junto a éstos de geógrafos e historiadores, los que han permitido una mayor aproximación de la historia literaria a los libros de viajes medievales. 
y luego también de Marco- se cuenta sólo en los primeros capítulos; después, consciente el narrador de que lo importante es la nueva realidad descubierta, irá presentando los distintos lugares y regiones, pero sin unirlas al armazón de un itinerario. Rustichello da Pisa, el redactor de la obra a partir del relato oral de Marco Polo y que ya no es un viajero, percibe con gran agudeza la novedad de lo contado y decide construir no un convencional relato de viajes, sino una más ambiciosa descripción o Divisament dou monde, como lo titula ${ }^{\prime \prime}$.

Lo habitual en el género es, sin embargo, que el itinerario ocupe la totalidad del texto. Ocurre así incluso en los viajes fingidos, como en el de Mandeville, que articula todos los lugares descritos sugiriendo al lector un itinerario, si bien impreciso e imposible, presentado a través de fórmulas narrativas como:

«De Chipre hombre va por mar a Jherusalem... et es hombre en un dia e en una noche qui ha buen viento al puerto de Thir...»,

«Et qui quiere ir mas lueint por mar e mas acercar a Jherusalem hombre va de Chipre al puerto de Jaffe...n. "Despues de Constantinoble va hombre a Rodas que ay bien cerca de cviij legoas por mar, et de Rodes a Chipre do ay bien cv legoas», etc. 12

Fórmulas que van ensartando ciudades y lugares, que unos tras otras y con mayor o menor detalle irá describiendo el narrador, aunque en este caso mayoritariamente a partir de materiales prestados y librescos ${ }^{13}$. Más preciso, aunque no menos ficticio e imposible, es el

11 El primer viaje de los hermanos Polo tuvo lugar entre 1260 y 1269 ; el segundo lo iniciaron en 1272, esta vez acompañados por el joven Marco, quien permanecería largos años en la corte de Kubilai Khan. A su regreso a Italia en 1298, y hecho prisionero por los genoveses, Marco Polo llevaría a cabo, en la misma cárcel y con la colaboración del escritor Rustichello da Pisa, la composición de su libro. Originariamente la obra fue escrita en lengua francesa con abundantes italianismos y se difundió con el título de Le divisament dou monde. El título de $I l$ Milione que recibió en las redacciones italianas deriva de un sobrenombre con que era conocida la familia de los Polo. Para los datos histórico-literarios y la bibliografía sobre el libro, puede verse Cesare SEGRE: «Le forme e le tradizione didattiche», en Grundriss der Romanischen Literaturen des Mittelalters, Heidelberg, 1968-1970, V, 1, págs. 141-142, y VI, 2, págs. 196-197.

12 Ed. cit. de P. Liria Montañés, págs. 44,45 y 53 , cuyo texto modernizo ligeramente.

13 Aunque no se conoce con certeza la identidad del autor, el libro es comúnmente reconocido como obra del inglés John de Mandeville. Durante un tiempo fue tenido por viaje verdadero de este personaje que, en el primer cuarto del siglo XIV, habría peregrinado a Jerusalén, continuando luego ruta por los países 
itinerario que describe el Libro del conosçimiento, donde con gran celeridad y en un corto número de páginas se traza un impresionante recorrido que viene a dividirse en tres etapas: una por la Europa occidental (Sevilla, Portugal, Galicia, Navarra, Francia, Inglaterra, Irlanda y regreso de nuevo a España), otra por el este de Europa y Oriente (Francia, Italia, Hungría, ruta de Tierra Santa, Jerusalén, Egipto, norte de Africa) y otra por Africa y Asia (Marruecos, Guinea, Canarias, Africa ecuatorial, Etiopía, Arabia, India, Persia, Bizancio, Grecia, Turquía, centro Europa y regreso a Sevilla). El itinerario como elemento estructural del relato tampoco falta en la fábula geográfica que es el Libro de don Pedro de Portugal, donde, efectivamente, se cuenta el viaje del Infante y sus acompañantes "para ir a ver las partidas del mundo», desde su salida de Barcelos y recorrido por Castilla, Venecia, Chipre, El Cairo, Jerusalén, el Sinaí, Judea, hasta llegar al señorío del mítico Preste Juan, en Asia la mayor, donde concluye el viaje con la entrega de la carta del rey de León y la que a su vez envía a Occidente el Preste Juan.

Pero los itinerarios más característicos, completos y precisos como verdaderamente vividos son los de la Embajada a Tamorlán y las Andanças de Tafur. En la Embajada el itinerario comprende «todos los lugares e tierras" que recorrieron los embajadores de Enrique III, desde Cádiz a Samarcanda, y regreso de nuevo a España, a Alcalá de Henares. Ese itinerario, como señala F. López Estrada ${ }^{14}$, tiene dos fases bien diferenciadas: una, por vía marítima, desde Cádiz a Trebisonda, en los confines del mar Negro, y otra, por tierra, desde Trebisonda a Samarcanda, capital del imperio de Tamorlán. Recorrido que naturalmente vuelve a desandarse al regreso. La primera es un viaje costero por el Mediterráneo: Mallorca, Córcega y Cerdeña, puerto de Gaeta, costa italiana hasta Mesina, de donde pasan a Rodas y desde allí, por el mar Egeo y la costa turca, al puerto de Pera y Constantinopla en el mar de Mármara, para luego, a través del Bósforo y el mar Negro, llegar a Trebisonda. En la segunda, aún con más riesgos y dificultades, los embajadores se internan en tierra, por regiones de Armenia (Erzurum, Aunique) y Persia (Tabriz, Sultania, Teherán) hasta llegar a Samarcanda en Asia central, en el actual Uzbekistán. El itinerario es así un per-

musulmanes, la India, China, hasta regresar a Europa hacia 1350. Hoy, sin embargo, la opinión más extendida lo considera como libro de viajes ficticio, que toma la mayor parte de sus noticias de otros viajeros de la época y, sobre todo, de fuentes eruditas clásicas y enciclopédicas (Plinio, San Isidoro, Vicente de Beauvais, etc.).

14 LÓPEz Estrada, F.: *Viajeros españoles en Asia: La embajada de Enrique III a Tamorlán», Rev. de la Universidad Complutense, 3 (1981), págs. 227-246. 
fecto recorrido lineal de ida y vuelta -ésta mucho más acelerada en el relato- y cuyo momento y núcleo principal lo constituye la estancia en la corte de Tamorlán.

El itinerario del libro de Tafur es algo más complicado, aunque a lugares no tan lejanos. El viaje, también por mar y por tierra, tiene ahora cuatro etapas y, como centro de operaciones, la ciudad de Venecia ${ }^{15}$ : la primera comprende de Sanlúcar de Barrameda (aunque seguramente la salida seria desde Sevilla, pero falta parte del primer folio del manuscrito) a Venecia, con visita a Roma y otras ciudades italianas; la segunda es un viaje a Oriente, desde Venecia, recorriendo Palestina, Egipto, Turquía, Bizancio y regreso a Venecia; la tercera es un viaje al imperio alemán y ciudades limítrofes de los Países Bajos, Polonia, Austria, Italia hasta Ferrera y de nuevo Venecia; la cuarta es el regreso a España por el Adriático y las costas del Mediterráneo hasta Cerdeña (aquí se interrumpe el manuscrito, también falto de algún folio al final, donde probablemente se continuaría el viaje hasta la llegada a Sevilla). En este caso, y a pesar de ese aparente orden, se trata de un viaje más azaroso y de aventura que la Embajada: en realidad, no hay un punto determinado al que se dirija el viajero y del que retorne sin más conforme a un plan previamente trazado. Por eso no es infrecuente que en distintos momentos Tafur haga incursiones a nuevos e imprevistos lugares: en el mar Negro, por ejemplo, se separa del grupo de peregrinos al que acompañaba para llegarse hasta Trebisonda y Cafa; desde el Sinaí quiere pasar a la India, aunque le disuadirá Nicoló dei Conti; desde Brujas y la Picardía hubiese querido continuar hasta París, aunque acaba desistiendo por temor a la peste que asolaba aquellas regiones, etc.

\section{El orden cronológico}

En el trazado de ese itinerario el narrador se ve obligado a adoptar también un orden cronológico -el tiempo que dura el recorrido-, con el fin de dar cuenta, más o menos puntual, del desarrollo y de la historia del viaje. No se trata de una absoluta dependencia del tiempo, como ocurre en la crónica o en la biografía, pero sí de enmarcar en un cuadro cronológico las andanzas viajeras. Naturalmente, este orden cronológico será tanto más estricto cuanto más objetiva y fiel a la realidad histórica se muestre la relación del viaje -cuanto más próxima esté de la crónica- y me-

15 Vid. José Vives, Andanças e viajes de un hidalgo español (Pero Tafur, 1436-39), Barcelona, 1947, págs. 27-56, donde se hace una exposición muy precisa y detallada de este esquema del viaje. 
nos cuanto más fabuloso sea éste y más nos aproximemos a la novela.

La Embajada a Tamorlán, que no es sino la crónica de un viaje oficial a instancias del propio rey, adopta un rigurosísimo orden cronológico seguido prácticamente día por día. De manera que la secuencia del relato progresa a través de fórmulas temporales como éstas:

«Domingo seguiente que fueron quatro días del dicho mes de mayo, llegaron a la çiudad de Arzinga (...) Otro día, lunes, el señor de aquella çiudad fezo dar çierta contía de dineros de que se mantoviessen mientra allí estoviessen (...) E martes seguiente non les fizieron fiesta ninguna (...) Otro día, miércoles seguiente, después de comer envió por los dichos embaxadores (...) Los dichos embaxadores estovieron en esta çiudad de Arzinga fasta jueves que fueron quince días del dicho mes de mayo, que partieron de allí $(\ldots){ }^{16}$.

Con ello el libro resulta un auténtico diario, una crónica cotidiana de los sucesos y escenarios del viaje, desde el exacto día de la partida (Puerto de Santa María, 21 de mayo de 1403) al de la llegada (Alcalá de Henares, 24 de marzo de 1406). Cada día viene a formar así una unidad narrativa en la que se insertan las correspondientes descripciones de lugares y relación de sucesos, y que variará en su extensión según el número y la importancia de éstos. En ese esquema habrá también pocos hiatos y lagunas de tiempo, y éstas sólo motivadas por la falta de incidentes que contar, aunque, incluso en esos casos, también se sentirá obligado el narrador a dar cuenta del fluir del tiempo:

"estovieron alli el dicho día martes que $\gamma$ llegaron, e miércoles, e jueves, e viernes, fasta el martes seguiente, que non podían salir del puerto (...)».

Adoptada esa perspectiva de actualidad y de proximidad a los hechos -el libro se escribió conforme transcurría el viaje, según se desprende de lo que afirma su autor en el prólogo: "Començé a escribir desde el día que los embajadores llegaron al Puerto de Santa María"-, el relato ofrece una gran precisión y veracidad en lo que cuenta, desde la exacta localización de los lugares que recorren y las distancias entre ellos, hasta los sucesos que acaecieron, las per-

${ }^{16}$ Ed. cit. de López Estrada, F., págs. 84-95, que modernizo. 
sonas que encontraron y toda suerte de detalles descriptivos (costumbres, usos del comercio, organización política) ${ }^{17}$.

Las Andanças de Tafur no responden ya a un orden cronológico tan estricto, y las indicaciones temporales son mucho más esporádicas e imprecisas: "e aquel día e la noche siguiente navegamos...», "estovimos ahí tres días...", «en Roma estuve toda la quaresma...», "en Venecia estuve treinta días e más esperando fasta el día de la Ascensión...», etc. No obstante, hay un tiempo real perfectamente respetado y que se puede reconstruir a partir de las referencias internas del texto. Atendiendo diligentemente a ellas, José Vives supo establecer una minuciosa cronología del viaje, que iría del otoño de 1436 a la primavera de 1439.

Frente a lo que veíamos en la Embajada, en el libro de Tafur el tiempo de la escritura está ya bastante alejado del tiempo de la experiencia, por lo que hay que considerarlo, más que como un diario de viaje, como una crónica restrospectiva. El libro, efectivamente, está escrito tiempo después de concluido el viaje: en el texto no son raras las referencias a un presente distinto (al hablar de la ciudad de Cafa, por ejemplo, afirma: "Allí compré yo dos esclavas e un esclavo, los quales oy tengo en Córdova») y por algunas de ellas, como la que se hace a la muerte de Juan II o a la caída de Constantinopla, se infiere que el libro se componía hacia 1454, esto es, catorce 0 quince años después del viaje ${ }^{18}$. Tafur redacta, pues, su obra desde el recuerdo; sin duda, con la ayuda de notas tomadas en el viaje, pero sin someterse ya a un imperioso y pautado ritmo temporal. Ello determina que pueda hacer del relato una construcción algo más ordenada, cuidando, por ejemplo, de distribuir proporcionalmente la descripción de lugares a la ida y a la vuelta, o que seleccione materiales y sucesos y a algunos pueda darles una función más artística en el relato (así, el encuentro con Nicolò dei Conti, del que luego trataremos). Al propio tiempo, ese alejamiento de los sucesos será causa de algunas imprecisiones y errores, con las que, por cierto, algunos críticos han querido rebajar la autenticidad del libro, y que explicablemente se producen al tratar de precisar la distancia y ubicación de algunos lugares o la fecha de algún acontecimiento histórico ${ }^{19}$.

17 Sobre la veracidad y exactitud del relato, vid. el estudio de López EsTraba en su ed. cit., págs. CCXXVIII-CCXXXIII.

18 Para la cronología del viaje y la fecha de composición de la obra, cfr. José Vives, ob. cit., págs. 20-27.

19 Vid. también J. Vives, ob. cit., págs. $17-19$ y 57-74, donde con buenos argumentos trata de justificar aquellas confusiones frente a la opinión de criticos como Morel-Fatio o C. Desimoni que habían puesto en duda la veracidad de Tafur. 
El orden cronológico, por último, prácticamente no existe en los viajes fingidos. En el Libro del conosçimiento hay apenas alguna rarísima y vaga indicación temporal («e allí moré un tiempo...n). En el Libro del infante don Pedro no existe tampoco un marco temporal, aunque sí de manera esporádica referencias a la duración del traslado de un sitio a otro o a la estancia en un determinado lugar ( $\propto$ de allí fuemos para el Valle de Josafat y andovimos por él siete dias...", «llegamos un lunes por la mañana e allí estovimos nueve días...", etc.). Pero se trata más bien de simples fórmulas expresivas, sin referente real ni continuidad en el texto, inducidas por las convenciones del género y que el narrador utiliza para dar mayor cohesión textual y verosimilitud a su relato.

\section{El orden espacial}

Con todo, lo más importante en el libro de viajes, lo que crea su verdadero orden narrativo, es el espacio -y no el tiempo-, los lugares que se recorren y se describen. En principio, diríamos que en este punto hay un propósito totalizador, de describirlo todo, de incorporarlo todo al relato, aunque sólo sea mediante su simple mención. El Libro del conosçimiento, que es algo así como un relato cartográfico, como un inmenso mapa desplegado en palabras ${ }^{20}$, trata de comprender nada menos que «todos los reinos e tierras e señoríos que son por el mundo» $y$, si bien sólo nombrándolos, está a punto de conseguirlo. Aunque con propósitos menos ambiciosos y sí más ceñido a un itinerario concreto, la Embajada a Tamorlán tampoco desdeñará la incorporación al texto de todos y cada uno de los parajes que recorren los embajadores por insignificantes que sean, produciéndose con ello un espectacular amontonamiento de nombres y lugares. Pero, a pesar de ese primer impulso totalizador, en el libro de viajes no todo es de la misma importancia para el viajero, por lo que el narrador se verá obligado a elegir y seleccionar los hitos fundamentales del itinerario. Esos puntos privilegiados serán, precisamente, las ciudades.

En el libro de viajes, en efecto, la ciudad se convierte en el índice de referencia esencial a través del cual progresa la descripción del itinerario. De esa manera, las ciudades se van constituyendo en los verdaderos núcleos narrativos en torno a los que se organiza el resto del relato, la relación del viaje. Hasta el extremo de que, cuando no existen ciudades en una etapa del itinerario que se sigue, se

$20 \mathrm{M}$. Jiménez de la Espada aludió ya a su relación con los atlas más conocidos de la época, como el de los venecianos Pizigani y el anónimo catalán o mallor. quín (ed. cit.). 
produce una brusca aceleración del tiempo de la narración: cuando Tafur parte de Milán y toma el camino de Alemania, hacia Basilea, por toda indicación sobre esa etapa del viaje, en la que no cuenta nada $\mathrm{y}$, sin embargo, le lleva tres días, se siente obligado a decir: «E porque non fallé tal çibdat para que della faga mençión, non lo escrivo aquí" "21. En cambio, la presencia de una ciudad importante -como Constantinopla, Venecia o Roma- retarda el ritmo temporal y alarga considerablemente la narración: la descripción de Venecia ocupa en el libro de Tafur más de veinte páginas, dieciséis la de Roma, diez la de Cafa, etc. (lo mismo en la Embajada: ocho páginas Constantinopla, seis Trebisonda, etc.).

Ahora bien, lo más notable es que la descripción de las ciudades se hace siempre conforme a un esquema compositivo fijo que se repite igual en todos los relatos, aunque con las correspondientes variaciones amplificativas. Ese esquema, a nuestra manera de ver, procede de la antigua tradición retórica y es el que catalogan algunos textos, como los Excerpta rhetorica del siglo IV, en el apartado de laudibus urbium. Sustancialmente, conforme alli se recomienda, la descripción debe atender a los siguientes aspectos: a la antiguiedad y fundadores de la ciudad (urbium laudem primum conditoris dignitas ornat), a su situación y fortificaciones (de specie moenium locus et situs, qui aut terrenus est aut maritimus et in monte vel in plano), a la fecundidad de sus campos y aguas (tertius de fecunditate agrorum, largitate fontium), a las costumbres de sus habitantes (moribus incolarum), a sus edificios y monumentos (tum de his ornamentis, quae postea accesserint), a sus hombres famosos (si ea civitas habuerit plurimos nobiles viros, quorum gloria lucem praebeat universis); para todo ello, en fin, se encarece el uso de la comparación, como era propio de todo el género epideíctico (in his quoque faciemus breviter comparationem) ${ }^{22}$. Tal esquema, muy difundido por toda la Edad Media en el panegárico de ciudades y países ${ }^{23}$, es el que encontramos aplicado una y otra vez en nuestros libros de viajes, más o menos alterado el orden de sus elementos y, eso sí, casi siempre muy diluido en virtud del intenso empleo de

21 Ed. cit. de Jiménez dE la EsPada, M., pág. 230.

22 Excerpta rhetorica, en Rhetores latini minores, ed. C. Halm, Leipzig, 1863, págs. 585-589. José Vives, ob. cit., pág. 15, señaló también que las descripciones de ciudades en el libro de Tafur respondían a un xorden sistemático», aunque no llegó a advertir la vinculación y procedencia retórica de éste.

23 Vid. Robert Curtius, E.: Literatura europea y Edad Media latina, trad. esp., México, 1955, págs. 228-229. Nótese cómo aquel esquema retórico todavia funcionará con eficacia en la novela picaresca, género que también privilegia notoriamente la descripción de ciudades (vid. Cros, Edmond, Protée et le gueux, Paris, 1967, págs. 288-304). 
la amplificación, que lo interrumpe y ensancha considerablemente. Citaremos sólo dos ejemplos, entre los muchos que podrían aducirse, la descripción de Constantinopla en la Embajada a Tamorlán:

"La çiudat de Constantinopla es muy bien çercada de alto muro e fuerte, e de fuertes torres e grandes (...) e las dos partes della çerca la mar, e la otra la tierra; e al un cabo, a la esquina que non çerca el mar, en un alto, están los palaçios del emperador (...) ha muchos oteros e valles en que ha labranças de panes e de viñas, e muchos huertos (...) ha fuertes pozos de agua dulçe (...) otrosí por esta çiudat de Costantinopla ay muy grandes edefiçios, de casas, e de iglesias, e de monesterios (...) e dizen que oy en día ha en esta çiudat bien tres mill iglesias entre grandes e pequeñas (...) E la çiudat de Costantinopla está junto con el mar, como vos he dicho, e las dos partes della çerca el mar; e de fruente della está da çiudat de Pera, e entre amas las çiudades está el puerto; Costantinopla está así como Sevilla, e la çiudat de Pera así como Triana, e el puerto e los nabios en mediox ${ }^{24}$.

- la de Génova en las Andanças e viajes de Tafur:

*Esta çibdat es muy antiquíssima, dizen que la pobló Ianus, prínçipe de Troya, después que vino de la destruiçión della. $\mathrm{E}$ bien paresçe fecha de mano de onbre vençido, que la asentó en una muy áspera montaña sobre la mar, e todas las casas son torres de quatro o çinco sobrados o más, e muy angostas las calles, e muy ásperas entradas; la tierra muy flaca de todos mantenimientos, pero gente muy industriosa (...) Tiene buen puerto (...) monesterios muy notables, iglesias ansí mesmo; la iglesia mayor, que se llama Sant Juan Lorençe, muy notable, espeçialmente la portada; aquí tienen ellos el Santo Vaso, que es de una esmeralda, maravillosa reliquia (...) Esta çibdat con todo su patrimonio se rige a comunidad (...) e es gente muy pujante por la mar, mayormente sus carracas son las mejores del mundo $(.) \times$.25 .

En torno a ese núcleo narrativo que forma la descriptio urbis se organizará ya todo el relato mediante la puesta en práctica de los comunes procedimientos amplificativos y digresivos. El marco de la ciudad, la llegada a ella, dará ocasión para contar el mundo visto

24 Ed. cit., págs. 56-58; pueden verse también, algo más concisas y ajustadas, las descripciones de Arzinga, págs. 88-89, Azeron (Erzurum), pág. 96, Turis, págs. $106-107$.

25 Ed. cit., págs. 12-14; véanse también las descripciones de Pera, pág. 186; Brujas, pág. 251; Nuremberg, pág. 269; Milán, pág. 277-278; Viena, pág. 281, etc. 
y experimentado: el recibimiento y audiencias de los mandatarios del lugar, lo que a su vez permite describir el ceremonial cortesano, las fiestas, los vestidos, los usos de la corte y la organización política (todo ello de primordial importancia en la Embajada, pero también muy estimado por Tafur); las visitas a edificios y monumentos, lo que da pie a digresiones religiosas sobre el culto, las reliquias $o$ leyendas hagiográficas; el encuentro con gentes particulares, cuya historia o leyenda se narra. De igual modo, podrán introducirse también digresiones sobre la propia historia de la ciudad y sus relaciones políticas con otros lugares, sobre sus personajes famosos, sobre las costumbres y modos de vida (carácter de sus gentes, hábitos en el vestir o en el comer, sus medios de trabajo, sus mercados) o sobre los productos de la región, plantas, piedras preciosas, animales, etc.

Algunas veces, sin embargo, el procedimiento amplificativo se verá contrarrestado por el opuesto de la abreviatio. Así, en la Embajada al describir los palacios de la ciudad de Quix: «E allí les mostraron tantas cámaras e apartamientos que sería luengo de contar (...) e tanta e tan rica era la obra destos palaçios que se non podría bien escrivir»; o Tafur cuando describe Gante: "Bien avríe que dezir desta çibdat, sinon por non alargar e enojar con escriptura", o la feria de Amberes: "E non sé cómo podiesse escrevir un fecho tan grande como este desta feria desta çibdat» ${ }^{26}$. La combinación, más o menos hábil, de estas técnicas de la repetitio (en el esquema retórico de la descripción de ciudades), la digressio y la abreviatio viene a constituir, pues, el procedimiento fundamental de disposición y desarrollo del discurso en el libro de viajes.

\section{Los «mirabilia»}

Parte muy especial de aquellas digresiones ocupan lo que esos mismos libros llaman las «maravillas». Era también, de seguro, lo que más atraía la atención y lo que generosamente venía ofreciendo el relato de viajes desde sus primeras muestras medievales, incluso destacándolo muchas veces en el título (los Mirabilia descripta, de Jordanus; el Libro de las cosas maravillosas de Marco Polo o el Libro de las maravillas del mundo, de Mandeville, como se conocieron estas dos obras en sus traducciones al castellano). Lo maravilloso, dicho brevemente, estaba constituido en gran medida por lo extraordinario, lo fabuloso que había propagado la leyenda de Oriente y que poblaba la imaginación del hombre medieval. Era la concepción creada de un Oriente insólito, desconocido y casi increíble,

26 Embajada, ed. cit., pág. 150; Andanças, ed. cit., págs. 258 y 260. 
que se había difundido por la Edad Media a través de muy diversos conductos: desde la ciencia enciclopédica (bestiarios, lapidarios, cosmografías, tesoros, que prácticamente se limitaban a recoger las noticias de autores antiguos como Plinio, Pomponio Mela o Solino) hasta las leyendas, de enorme impacto, de Alejandro Magno y, sobre todo, la del Preste Juan de las Indias. Esta venía corriendo desde el siglo XII en una supuesta carta que el mítico Preste Juan dirigía al emperador de Occidente y en la que aquel extraño rey y sacerdote cristiano describía en los más fabulosos términos las tierras que estaban bajo su dominio: el país que señoreaba se extiende desde la India hasta el desierto de Babilonia, allí la tierra mana leche y miel, por él corre el río Ydonus que brota en el paraíso y arrastra piedras preciosas de todas clases, al pie del monte Olimpo hay una arboleda donde se encuentra la fuente de la Juventud, cerca de allí está el mar seco y el río pétreo, aquel país está poblado por los animales y seres más exóticos, como dromedarios, hipopótamos, cocodrilos y también grifos y sagitarios, y hay, en fin, hombres de un cuerno en la frente, gigantes, cíclopes, extraños pájaros y reptiles que no son venenosos 27 .

Muchos de esos materiales, convertidos ya en lugar común, serán recogidos e incorporados al libro de viajes medieval. Pero es sobre todo en los viajes fingidos donde más abunda ese tipo de maravilloso fantástico. Así ocurrirá, por ejemplo, en el libro de Mandeville, quien, muy consciente de la fascinación de aquellos materiales («porque muchos toman plazer y solaz en oír fablar las cosas extrañas», afirma en el prólogo), cuidará de empedrar su relato con toda suerte de curiosidades y maravillas: el ave fénix, las manzanas del paraíso, el bálsamo, los graneros de José, las propiedades de los diamantes, los etíopes de un solo pie pero tan grande que puede servirles de sombrilla, etc., o multitud de leyendas fantásticas, como la de la doncella de la Isla del Lago convertida en dragón hasta que un caballero la bese en la boca, o la del mancebo de la ciudad de Sietelías que engendró un monstruo de su amada muerta, aparte de las múltiples relaciones de milagros, leyendas de santos y de reliquias. También esas maravillas recibidas de la leyenda o de la tradición enciclopédica abundan en el Libro del conosçimiento, donde se describen, entre otras: los hombres sin cuello y con la

27 La primera redacción latina de la carta fue publicada por Friedrich Zarncke en 1879; el texto anglonormando puede verse en HilkA, Alfons, «Die anglonormannische Versversion des Briefes des Presbyters Johannes», Zeitschrift für französische Sprache und Literatur, XLIII (1915), págs. 82-112, y una vulgarización francesa en prosa, en Jubinal, A.: Oeuvres de Rutebeuf, III, págs. 356-375. 
cabeza en el pecho, que el autor sitúa en Noruega; o los hombres perro, los cinocéfalos, que viven en Tartaria, y de los que afirma: "Yo vi uno de ellos en la ciudad de Norgancio»; o los árboles que dan como fruto grandes pájaros, en Irlanda. Y lo mismo ocurre en el Libro del infante don Pedro, que además ya utiliza como material maravilloso la carta del Preste Juan, el libro de Mandeville e incluso el relato de la embajada a Tamorlán.

Sin embargo, mucho más importante en este aspecto será el descubrimiento de lo maravilloso real que ofrecen los libros de viajes verdaderos y que seguramente es la gran aportación al género del libro de Marco Polo, quien por primera vez da cuenta de un mundo insólito y desconocido, pero absolutamente real, visto y experimentado por él, y que causará asombro en Occidente. Ese maravilloso, que en realidad no existe como tal, sino que viene a ser lo no observado cotidiana y familiarmente, es el que describen con una gran modernidad libros como la Embajada a Tamorlán y las Andanças de Tafur. En el primero, ese maravilloso se encuentra, por ejemplo, en la grandiosidad impresionante de Constantinopla y el esplendor de los mosaicos de Santa Sofía, o en el paisaje imponente que comienza en Trebisonda, o en la suntuosidad del campamento de Tamorlán y todo su ceremonial cortesano. Y en el libro de Tafur puede descubrirse en la visión magnífica de la Roma decadente y medieval; o en la descripción de la ribera del Nilo, donde estuvo un mes "mirando muchas cosas e muy estrañas, mayormente a los de nuestra naçión» (la alcaicería de El Cairo, pobladas sus calles de multitud de bazares y vendedores ambulantes, las huertas de Matarea donde nace el bálsamo, los cocodrilos - cocatrices- e hipopótamos en la orilla del Nilo, los graneros de José, los elefantes y jirafas); o en la gran fábrica de la ciudad de Venecia; o la ribera del Rin, de la que afirma: "Es sin duda la más fermosa cosa de ver en el mundo.»

La contemplación de todo ello causa gran asombro y admiración en el viajero - que querrá transmitirlo a sus lectores-, pero también trata de racionalizarlo trasladando allí sus hábitos de observación más familiares. La comparación será de nuevo el procedimiento más eficaz para la descripción de todas estas cosas maravillosas: los elefantes («marfiles») que el autor de la Embajada contempla en el campamento de Tamorlán, «eran negros e non han pelo ninguno, salvo en la cola que han como cavallo que han unas pocas de sedas; e eran grandes de cuerpo, que podían ser quatro o çinco toros grandes; e el cuerpo han mal fecho, sin talle, como un grand costal que estudiese lleno...n; los graneros de José (las pirámides) para Tafur «son fechos a manera de un diamante con 
aquella punta arriba tan aguda; será el altura mucho más que la torre mayor de Sevilla” ${ }^{28}$.

Por eso, ante lo que no es fácil o no es posible racionalizar, el viajero se suele mostrar escéptico o reticente. Tafur, que no pudo llegar a la India, se las ingenia para tratar de ella incorporando a su libro el relato de Nicolò dei Conti, pero a la pregunta obligada de "si avía visto cosas mostruosas en la forma humana, ansí como algunos quieren dezir onbres de un pie o de un ojo, o tan pequeños como un cobdo o tan altos como una lança», se limita a transcribir la escueta respuesta del veneciano: «Dize que non sintió nada de todas estas cosas, pero que bestias vido de estrañas figuras." De igual modo, cuando en Espalato recoge las noticias sobre un monstruo marino, mitad hombre y mitad pez, que fue capturado y enviado a Venecia, se siente obligado a precisar: «Esto yo non lo vi, pero dicho me fue e que avía poco que avía acaesçido.» Tal actitud le lleva en algún caso a exhibir un peligroso - y casi preerasmistaescepticismo: cuando en Nuremberg le mostraron la supuesta lanza que atravesó el costado de Cristo, "yo dixe cómo la avía visto en Costantinopla, e creo que, si los señores allí non estuvieran, que me viera en peligro con los alemanes por aquello que dixe ${ }^{29}$.

\section{La forma de presentación del relato}

El itinerario constituye, como quedó dicho, la materia narrativa esencial para el autor del libro de viajes, que se limitará a seguirlo, a contarlo en su desarrollo único y lineal, mediante la técnica combinada de la repetitio, la digressio y la abreviatio, ya comentada. Lo que. sin embargo, no hay en el libro de viajes - frente a lo que es muy común en otras formas de la narrativa medieval- son entrelazamientos, acciones paralelas, que obliguen al narrador a interrumpir o dejar en suspenso su relato. Estamos ante una pura narración lineal y continuada, que protagoniza también un solo personaje -individual o colectivo, real o fingido- y que, además, es casi siempre el propio narrador de la historia. Esta identidad entre el protagonista y el narrador impone de ordinario la primera persona como forma de presentación del relato. Así están escritas, por ejemplo, las Andanças de Tafur ("Fezimos vela e salimos del puerto de Barrameda; e yo iva en una nao de Galliçia..."), y es también el procedimiento que adoptan los viajes fingidos, como el Libro del conosçimiento que ensambla la árida exposición geográfica con la imaginaria experiencia personal de un viaje real mediante la reiteración

28 Embajada, ed. cit., pág. 104; Andanças, ed. cit., pág. 86.

29 Ed. cit., págs. 106, 194 y 270. 
de la primera persona para introducir cada uno de los lugares catalogados ( Partí de Génova y entré en Lombardía... Partí de Lombardía y entré por Pisa... Salí de Pisa y entré por Toscana...x).

El empleo de esa primera persona contribuye, sin duda, a hacer más atractivo y sugeridor el relato al receptor, a quien transfiere más fácilmente, sin un narrador interpuesto, la experiencia vivida 0 imaginada ${ }^{30}$. Pero, sobre todo, tiene una función verificadora $y$ testimonial que refuerza la verosimilitud y autenticidad de lo narrado. No es, pues, extraño que recurran a ella los libros de viajes fingidos, y es muy significativo -y un gran acierto estilístico- que Tafur, que la mantiene a lo largo de todo el relato de sus andanzas vividas, cuando tiene que contar el «fecho de la India» (que no podía faltar en un libro de viajes, pero que son regiones adonde él no ha podido llegar), ceda su uso y lo haga por boca del famoso viajero Nicolò dei Conti. De todos modos, a pesar del empleo de la primera persona, lo privilegiado en estos libros de viajes medievales son los datos externos, no el mundo personal, el yo del viajero (lo que sólo ocurrirá en los géneros autobiográficos modernos). El protagonista es un simple espectador y anotador de los lugares y las cosas que observa, y a lo más que llega en este terreno de lo personal es, como Tafur, a contarnos si en determinado lugar sufrió una dolencia, o recibió una herida, o se rapó la barba y el cabello, o perdió sus dientes a causa del intenso frío.

De los libros españoles, sólo la Embajada a Tamorlán altera esa forma habitual de presentación del relato viajero y nos ofrece una narración más impersonal y objetiva en tercera persona (en raras ocasiones reemplazada por la primera de plural o de singular): «Lunes, que fueron veinte e un días del mes de mayo del año del nasçimiento del Señor de mill e quatroçientos e tres años, llegaron los dichos enbaxadores en el Puerto de Santa María... E luego, otro día, martes seguiente, que fueron veinte dos días de dicho mes, partieron de aquí en una barca...» Ese empleo de la tercera persona se debe, sin duda, al carácter cronístico y oficial que posee la obra, y en la que no hay tampoco un protagonista individual, síno más bien colectivo. Son los embajadores del rey Enrique III de Castilla, que actúan en una empresa diplomática que es ya historia verdadera y merecedora de perpetuarse en lo escrito: para que

30 La facultad que posee el libro de viajes de transferir de manera privilegiada las experiencias personales la ha subrayado bien Georges May, La autobiografia, trad. esp., México, 1982, págs. 162-163: *El viaje tiene de particular que interesa tanto a quien se le narra como a quien lo realizó en persona. Como lo dice la paloma de La Fontaine: Mon voyage dépeint / Vous sera d'un plaisir extréme. / Je dirai: 'J'étais ld; telle chose m'avint; / Vous y croirez être vous-méme'.. 
aquellos hechos «no caigan en olvido e mejor e más verdaderamente se puedan contar e saber», como se afirma en el prólogo. La tercera persona, propia de la historiografía oficial y de la crónica, era, pues, la forma de presentación que mejor realzaba la condición áulica y testimonial del libro y la que exigía aquel viaje histórico a la hora de escribirse. Su misma historicidad excusaba también cualquier artificio de verosimilitud.

En cuanto al Libro del infante don Pedro, que está entre el libro de viajes fingido y la biografía individual novelada, utiliza prácticamente siempre la primera persona de plural. El narrador, Gómez de Santisteban, que es uno de los componentes de la expedición de don Pedro, quiere en efecto presentar el viaje como una experiencia colectiva. Sin embargo, su atención ha de centrarse especialmente en la figura individual del infante, que es el verdadero protagonista de la historia, y cuidará de presentar ésta como una auténtica y gradual trama novelesca, desde el momento de la partida y las intrigantes peripecias del viaje (son apresados varias veces, don Pedro tiene que ocultar su personalidad, llora en alguna ocasión y está a punto de abandonar) hasta el desenlace que supone el encuentro con el Preste Juan y el intercambio de cartas.

\section{Libros de viajes E IDEOlogfa caballeresca}

En términos generales podemos decir que no es mucho lo que se sabe acerca de la personalidad e ideología de los autores de libros de viajes medievales. En la época más antigua fueron clérigos y gentes de iglesia, anónimos casi siempre, quienes escribieron aquellas guías de Tierra Santa y relatos de peregrinación. En España, las primitivas muestras del género, como La Fazienda de Ultra Mar o el mismo Libro del conosçimiento, son también obra de clérigos. Del autor de este último sabemos que fue un fraile franciscano que vivió a mediados del siglo XIV, seguramente en Sevilla, lugar donde comienza y termina su itinerario. Aunque no indica expresamente sus propósitos, su obra está inspirada por la idea clerical del saber: es un libro del aconosçimiento de todos los reinos e tierras e señoríos que son por el mundo» y también de alas armas y los señores» que los gobiernan; es decir, un tratado didáctico, una compilación geográfica con añadidos de historia política y heráldica.

En el siglo $\mathrm{XV}$, cuando, como dijimos, cobra su mayor desarrollo el género, la personalidad de sus autores y protagonistas ha cambiado apreciablemente. Son ahora cortesanos que cumplen una misión diplomática del rey, un caballero en busca de aventuras aprovechando una tregua de guerra o incluso el propio infante de Por- 
tugal. También el público a que iban destinados esos libros pertenecía a los círculos caballerescos y aristocráticos: las copias del libro de Mandeville circularon por bibliotecas nobiliarias, el marqués de Santillana poseyó seguramente un manuscrito del Libro del conosçimiento ${ }^{31}$, la Embajada va dirigida al rey y a sus cortesanos para que aquellos hechos «non cayan en olvido", Tafur dedica su tratado a don Fernando de Guzmán, comendador de la Orden de Calatrava, y de la obra del infante don Pedro se hacen cargo crónicas caballerescas como la de García de Salazar.

Los libros de viajes del siglo Xv responden, en efecto, más que a una ideología clerical y letrada o a una actividad mercantil, a la mentalidad y formas de vida caballerescas de la sociedad española del ocaso de la Edad Media. Como empresa que pone a prueba el valor y esfuerzo personal del caballero, concibe Tafur en el prólogo de su libro el "visitar tierras extrañas»:

"porque de la tal visitaçion raçonablemente se pueden conseguir provechos cercanos a los que proeza requiere, ansí engrandeçiendo los fijosdalgo sus coraçones donde sin ser primero conosçidos los intervienen trabajos y priesas, como deseando mostrar por obras quién fueron sus anteçesores, quando solamente por propias fazañas puede ser dellos conoçedora la gente extrangeras 32 .

Dentro, pues, del estado de la caballería es donde encuentra su plena justificación el recorrido de extrañas regiones, que enaltece y adorna las virtudes del caballero. No sorprende así que cuando Juan de Mena escriba un poema epideíctico en alabanza del infante don Pedro de Portugal, en la enumeración -como prescribia el génerode las virtudes y atributos del homenajeado, resalte particularmente la dedicación viajera de éste:

31 Para la difusión del libro de Mandeville, vid. Entwistze, W. J.: "The Spanish Mandevilles», M.L. R., XVII (1922), págs. 251-257. En los inventarios de las bibliotecas del conde de Benavente, del duque de Medina Sidonia y del marqués de Cenete también pueden encontrarse algunas referencias a libros de viajes (cfr. Ladero Quesada, M. A., y Quintanilla Raso, M.: C.: «Bibliotecas de la alta nobleza castellana en el siglo XV», en Livre et lecture en Espagne et en France sous l'Ancien Régime, Colloque de la Casa de Velázquez, Paris, 1981, págs. 47-62). Uno de los códices del Libro del conosçimiento, según las indagaciones de JiMÉNEZ DE LA ESPADA, M., ed. cit., págs. XII-XIII, hubo de formar parte de la biblioteca del Infantado.

32 Ed. cit., págs. 1-2. 
Nunca fue después ni ante quien viesse los atavíos y secretos de Levante, sus montes, ínsoas y ríos, sus calores y sus frios, como vos, señor Infante. Ante moros y judios esta gran virtud se cante (...) ${ }^{33}$.

Por lo demás, el viaje a lejanas tierras es empresa que acometen infatigablemente tanto los caballeros de la ficción -son las «salidas» famosas de los héroes caballerescos, desde Lanzarote, Perceval o Roboán hasta el propio Don Quijote-, como los caballeros de carne y hueso de la España de la época (Pero Niño, Juan de Merlo, Diego de Valera, etc.). Sobre la actividad viajera de éstos baste citar el testimonio de Hernando del Pulgar en sus Claros varones de Castilla:

*Yo por cierto no vi en mis tiempos ni leí que en los passados viniesen tantos cavalleros de otros reinos e tierras estrañas a estos vuestros reinos de Castilla e León por fazer armas a todo trançe como vi que fueron cavalleros de Castilla a las buscar por otras partes de la christiandad. Conosci al conde don Gonçalo de Guzmán e a Juan de Merlo. Conoscí a Juan de Torres e a Juan de Polanco, Alfarán de Bivero e a mosén Pero Vásques de Sayavedra, a Gutierre Quixada e a mosén Diego de Valera. E of dezir de otros castellanos que con ánimo de cavalleros fueron por los reinos estraños a fazer armas con qualquier cavallero que quisiese fazerlas con ellos. E por ellas ganaron honrra para sí e fama de valientes e esforçados cavalleros para los fijosdalgo de Castillaw ${ }^{34}$.

En todos nuestros libros de viajes es bien patente la orientación y el gusto caballeresco que los preside. Incluso el clerical Libro del conosçimiento acaba resolviéndose, como dijimos, en un tratado de geografía política y en una exposición heráldica de las armas de

33 Mena, Juan de: Obra lírica, ed., estudio y notas de M. A. Pérez Priego. Madrid, Alhambra, 1979, págs. 205-208.

34 Fernando del Pulgar, Claros varones de Castilla, ed., intr. y notas de R. B. Tate, Oxford, 1971, pág. 56. Pero Niño, según cuenta su cronista en El Victorial, recorrió en sus andanzas las aguas y costas del Mediterráneo, así como diferentes lugares de Francia e Inglaterra. Diego de Valera viajó por Francia y estuvo también en Praga, ante el rey de romanos; más tarde, a instancias de Juan II, visitó Dinamarca, Inglaterra y Borgoña: en la Crónica de Juan II y en la Crónica abreviada son recordados algunos episodios de aquellos viajes. 
cada uno de los lugares y señoríos. La Embajada es una relación de viajeros servidores del rey de Castilla, cuyo principal interés se centra en la descripción de las cortes que visitan (su ceremonial, protocolo, fiestas, banquetes, indumentaria). Tafur, por su parte, será quizá el viajero que más ostentosamente exhiba su condición caballeresca: en Constantinopla introduce una larguísima digresión para probarnos que su linaje entronca con el del emperador, en el Santo Sepulcro arma caballeros a dos alemanes y un francés, a la salida de Maguncia le asaltan trescientos hombres de armas, "pero a mí por ser cavallero ninguno llegó fasta que truxeron un cavallero que me quitó el espada e las espuelas»; en Xafusa asistió a un torneo, en varias ocasiones expone la superioridad del hidalgo sobre el villano (así, al leer e interpretar las inscripciones de las estatuas de Pasquino y Marforio, en Roma) y siempre resalta la magnanimidad caballeresca de quienes le reciben y acogen.

La literatura de viajes habría que adscribirla, por tanto, a la literatura de ideología caballeresca que aún preside el siglo XV castellano, en el que casi nunca se logró resolver felizmente la tensión permanente entre armas y letras ${ }^{35}$. Como se lee en El Victorial, según aconsejaba su maestro a Pero Niño:

«El que a de aprender e usar arte de cavalleria, non conviene despender luengo tiempo en escuela de letras» ${ }^{36}$.

Tampoco parece, en efecto, que los autores de libros de viajes poseyeran "escuela de letras" ni una afinada cultura humanística. Aunque se permiten exhibir en ocasiones un cierto conocimiento de la antiguiedad, se trata casi siempre de lo más legendario y trillado por la Edad Media: lo que procedía de la leyenda troyana y de la de Alejandro, o alguna rara y genérica alusión mitológica. Así, el Libro del conosçimiento recordará de pasada cómo Alejandro no pudo conquistar el imperio tártaro, o la Embajada hará mención de las guerras de Alejandro con Darío y Poro, así como, en las islas griegas, creerá reconocer el templo «que derrocara Paris quando rovara a Elena e quebrantara el ýdolo». En el libro de Tafur son aludidos

$35 \mathrm{Vid}$. Round, Nicholas G.: «Renaissance culture and its opponents in fifteenth-century Castile», M. L. R., LVII (1962), págs. 204-215; Russel., Peter: «Las armas contra las letras: para una definición del humanismo español del siglo XV», en Temas de La Celestina» $y$ otros estudios, Barcelona, 1978, págs. 207-239; SCUDIERI RugGIERE, Jole: Cavalleria e cortesia nella vita e nella cultura di Spagna, Módena, 1980.

36 Dfez de Games, Gutierre: El Victorial. Crónica de don Pero Niño, conde de Bueina, I, cap. XIX, ed. Juan de Mata Carriazo, Madrid, 1940, pág. 64. 
en varias ocasiones los héroes troyanos: la isla de Citarea le trae a la memoria el robo de Paris y Elena, frente al puerto de Tenedón evoca las ruinas de Troya y más adelante la «torre del Vituperio, donde dizen que Archiles fue fallado con Patroclo"; el mismo Tafur se siente orgulloso de una herida de flecha que recibió en los Dardanelos y se refiere a ella como "el golpe de flecha que recibí en Troya». Aunque también hay en el libro alguna alusión mitológica (Medea y el acarnero dorado") y se cita a algún autor antiguo (Salustio y Tito Livio), sólo existe un pequeño atisbo humanístico en el recorrido que hace el viajero por Roma, donde busca afanoso los vestigios de la antiguiedad y se lamenta del escaso recuerdo que queda de ellos. No obstante, y aparte de lo que tiene de tópico el lamento por la decadencia de Roma en la literatura de la época ${ }^{37}$, lo que en realidad ocupará a Tafur en esas páginas de su obra será la descripción única de la Roma cristiana y medieval.

En cuanto al estilo, tampoco participan siquiera de la moda retoricista y latinizante que inunda la prosa del siglo $\mathrm{xV}$, sino que permanecen anclados en los usos medievales más arcaicos. Frente al complicado período hipotáctico y al retórico ordo artificialis que fundamentará aquella prosa humanística, nuestros autores se aferran a la más arcaica y elemental construcción paratáctica que trocea el discurso en breves y reiterados períodos, pero que, por lo demás, resulta quizá el procedimiento que mejor se acomoda a la linealidad de la narración y a la descripción acumulativa y acelerada del libro de viajes. De igual modo, a excepción del ya comentado uso de la comparación, es prácticamente inexistente cualquier tipo de figuras y ornamentos retóricos. El léxico, también escasamente culto y latinizante, abundará en cambio en términos de la jerga cancilleresca, marinera y militar ${ }^{38}$.

De lo que hasta aquí hemos venido viendo, seguramente debe concluirse que los libros de viajes medievales no poseen un valor literario sobresaliente. $Y$, en efecto, puede que sean relatos un tanto confusos y desorganizados, donde -también en un pobre estilo-

37 Cfr. GRAf, Arturo: Roma nella memoria e nelle immaginazioni del medio evo, Torino, 1923, págs. 34 y ss., que recoge, a ese propósito, diversos testimonios de Petrarca, Ambrogio Camaldulense, Ciriaco d'Ancona, Poggio Bracciolini, Enea Silvio Piccolomini, Giano Vitale, etc.

38 Algunas observaciones sobre el estilo de la Embajada pueden verse en el estudio de LópEZ EsTrada, F., en su ed. cit., págs. CCXV-CCXL, y sobre el de Tafur en Meregalli, F., Cronisti..., cit., págs. 64-68. 
se acumulan episodios, noticias y lugares sin un orden constructivo artísticamente muy logrado. No obstante, como hemos pretendido, puede hacerse el inventario de un cierto número de rasgos y procedimientos literarios que, por elementales que sean, informan ese tipo de relatos. En la medida que ha sido posible dar cuenta de ellos y diferenciarlos de los de otras obras y géneros, creemos que hay que admitirlos como una técnica de composición particular bien conocida por los autores que a ella se aplicaban y de la que extraian no malos resultados. Esa técnica de composición ha de cubrir, asi, una parcela literaria autónoma en el difuso panorama de nuestra prosa narrativa de fines de la Edad Media.

$Y$ fuera de ese valor histórico-literario, que es el que aquí lógicamenie más nos ha interesado, no debe olvidarse tampoco la repercusión de estos libros de viajes en la historia de nuestra propia civilización. En ese terreno, su aportación más decisiva fue la de contribuir de manera notable a la ampliación del horizonte de conocimientos de la época. La fascinación por lo nuevo y lo desconocido que trasmitían aquellos relatos, junto a la propia experimentación del viajero que siempre dejaba un más allá y un misterio que desvelar, suponían un permanente acicate para nuevas empresas que culminarían con los descubrimientos geográficos de fines de la Edad Media. No sorprende, así, que Hernando Colón, al hablar en la Historia del almirante de las causas que movieron a su padre, afirme que, además de los fundamentos naturales y los indicios de los navegartes, fue también la «autoridad de muchos hombres doctos*, entre los que cita expresamente a Marco Polo y a Juan de Mandeville, quienes en sus obras «dicen que pasaron mucho más adentro del Oriente de lo que escriben Ptolomeo y Marino, y aunque suceda que no hablen del mar occidental, puede argüirse por lo que describen del Oriente que la India está vecina a Africa y Españas ${ }^{39}$.

39 Colon, Hernando: Historia del Almirante, ed. de Luis Arranz, Madrid, 1984, pág. 65. 